\title{
Focal reflex myoclonus ${ }^{1}$
}

\author{
G. G. SUTTON AND R. F. MAYER \\ From the Department of Neurology, University of Maryland School of Medicine, \\ Baltimore, Maryland 21201, U.S.A.
}

SYNOPSIS In a patient with reflex myoclonus limited to the right side of the body, stimulation of the right median nerve in the index finger or wrist elicited a very large somatosensory evoked response (SER) and a long loop $\mathrm{C}$ reflex which represents an electrically evoked myoclonic response. It is suggested that the pathway for the $C$ reflex is through peripheral nerve, dorsal funiculus of spinal cord, contralateral VP nucleus of thalamus, sensorimotor cortex, corticospinal tract, and anterior horn cell. The large SER, C reflex, and myoclonic jerks are presumed to result from a release effect causing increased excitability at central synapses along this pathway. The patient presented has a large atrophic vascular lesion involving the left frontotemporoparietal region and involvement of pathways through the right superior cerebellar peduncle to account for the neural dysfunction.

Myoclonus has been described as a manifestation of hyperexcitability of the nervous system and may vary from the contraction of a single motor unit to a whole muscle or group of muscles. The contractions may be single or repetitive, may occur in rhythmical or arrhythmical patterns, may be initiated by many stimuli such as visual, tactile, and auditory, and may occur during motor activity. Physiological studies of patients with myoclonus have shown that the muscle contractions may be associated with abnormal discharges in the electroencephalogram and that these patients may also have abnormal cortical evoked responses (Dawson, 1947; Watson and Denny-Brown, 1955; Halliday, $1967 \mathrm{a}, \mathrm{b})$. Most of the patients reported with myoclonus initiated by motor activity (action myoclonus) (Lance and Adams, 1963; Lance, 1968) have generalized contractions and the studies have centred around cerebral function. Little attention has been given to spinal or long loop reflexes. The present report describes a detailed electrophysiological study of a patient with myoclonus limited to the right side of the body.

1 Presented at the Society for Neuroscience, 29 October 1971, Washington, D.C. Supported in part from research grants (MH17006 and NSO6779) from the National Institutes of Health, U.S. Public Health Services.

\section{CASE REPORT}

The patient (M.H.) was well until the age of 66 years when she had a tonic seizure and onset of mild sensory and motor signs on the right side. An electroencephalogram (EEG) revealed spike activity in the left cerebral hemisphere. The patient was treated with phenytoin and phenobarbitone and improved. One year later she had a second similar episode. She again recovered and was said to function normally during the following year. Subsequently she developed intermittent jerking of the right fingers and hand. Neurological examination three years after the onset of the disorder revealed the following: dysarthric speech, nominal aphasia (she was righthanded), right inferior homonymous quadrantanopsia, mild right hemiparesis with hyperreflexia and the arm involved more than the leg or face, bilateral extensor plantar reflexes, slightly decreased sensation (especially touch and stereognosis on the right side), and myoclonic jerks on the right side. The myoclonus was most prominent in the fingers and hand but involved face, jaw, tongue, and foot. Palatal myoclonus was not observed. The myoclonus was sometimes regular but often irregular. It was increased by motor activity, decreased with resting and disappeared during sleep. With some movements the myoclonus became very severe, spreading to proximal muscles and to the left extremities. There was a terminal ataxic component to movements of the right extremities and this occurred in association with the myoclonus. 


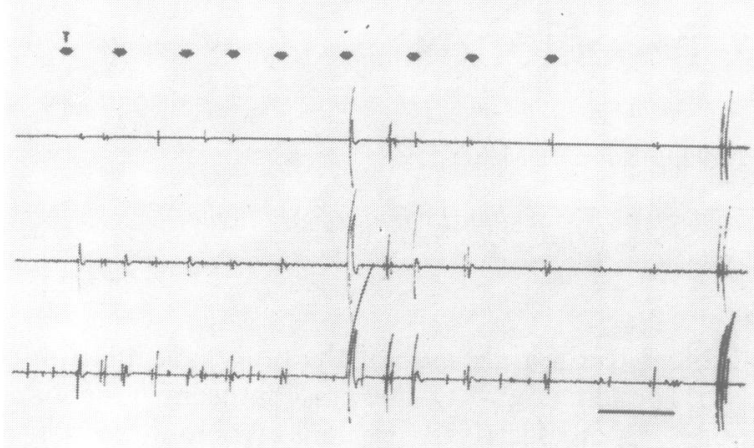

(a)

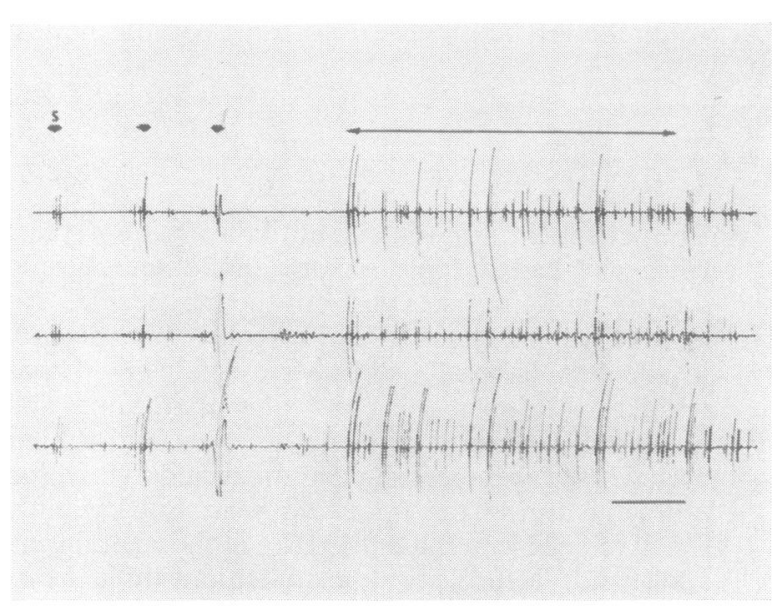

(b)

FIG. 1. Polygraphic recordings of myoclonic contractions evoked by (a) touch (T arrows) and (b) rapid stretching of muscle produced by eliciting single (S arrows) and repetitive (arrow) tendon jerks. Upper traces: right brachioradialis. Middle traces: right extensor muscles of wrist. Lower traces: right flexor muscles of wrist. Note greater response to muscle stretch. Calibrations: 5 sec.

A pneumoencephalogram revealed enlargement of the anterior portion of the left lateral ventricle. Arteriograms of the great vessels in the chest and neck and of the left carotid artery revealed atherosclerosis but no obstruction of any one vessel. Radiographs of the skull showed a calcified pineal gland which was $2.5 \mathrm{~mm}$ left of the midline. Cerebrospinal fluid examination was normal as was routine chemical analysis of the blood.

Seven years after the onset the patient was unable to walk, her speech was almost unintelligible, and she could not use her right upper extremity because of the myoclonus. The right visual field defect persisted, but the previous cerebral sensory dysfunction on the right side could not be demonstrated. Myo- clonus continued to be absent during sleep and complete rest. With motor activity it increased and was most prominent in the flexor muscles of the right upper extremity. The contractions were increased by? sensory stimuli and while eliciting tendon jerks. Although anticonvulsants decreased the amplitude of the myoclonus, none stopped it completely.

The electroencephalogram (EEG) remained abnormal with a diffusely dysrhythmic background and with paroxysmal discharges of spikes, polyspikes, $\frac{D}{2}$ and sharp waves which occurred especially in the left hemisphere, maximally in the central-temporal of region. Photic stimulation evoked a large cortical response in the occipital regions bilaterally.

The patient was considered to have cerebro- $\omega$ 


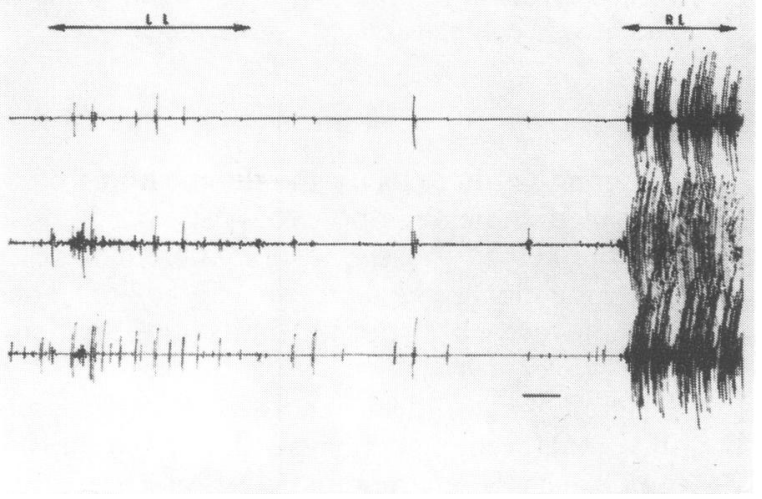

FIG. 2. Polygraphic recordings of myoclonic contractions as in Fig. 1. Note the moderate increase in the myoclonus on movement of the left leg (LL). With movement of the right leg $(\mathrm{RL})$, there is marked augmentation of the myoclonus. Calibration: 5 sec.

vascular disease with infarction in the left cerebral hemisphere involving the frontotemporoparietal area. Whether this lesion extended to involve deeper structures such as the thalamus was not established. There were no segmental brain-stem signs, although the incoordination of movement in the right extremities suggested involvement of pathways through the right superior cerebellar peduncle. The patient has been carefully observed over a period of four years, and no significant change has occurred in her neurological status.

\section{METHODS}

Motor and sensory nerve conduction velocities were determined in the median and posterior tibial nerves using standardized techniques (Mayer, 1963). Recordings of monosynaptic $\mathrm{H}$ reflexes in calf muscles (Magladery and McDougal, 1950; Mayer and Mawdsley, 1965) and antidromic motor $F$ responses in small hand and foot muscles (Magladery and McDougal, 1950; Mayer and Feldman, 1967) were made using surface disc recording electrodes. Electromyographic (EMG) activity was recorded from flexor and extensor muscles of all extremities using surface silver disc electrodes placed so as to record the myoclonus in fingers and hands. The electrical activity was amplified and recorded on an ink writing polygraph (Grass P5). Recordings were made at rest and during sensory stimulation, muscle stretch reflex testing, and movement. In some studies, EEG activity was recorded simultaneously with EMG activity.

During the studies to determine whether an $\mathrm{H}$ reflex was present in all small hand or foot muscles, a consistent late response was recorded. This electrical response, which we have designated the $\mathrm{C}$ reflex, occurred at the same time as a clinical myoclonic contraction and appears to represent an electrically evoked myoclonic jerk. The median nerve at the elbow, wrist or in the index finger or the posterior tibial nerve at the knee or ankle were stimulated via surface electrodes by a constant voltage square wave electrical pulse of short duration $(0 \cdot 1-0.5 \mathrm{msec})$ from a pulse generator through an isolation unit. The stimulus intensity was adjusted to evoke a just noticeable or a maximal motor (M) response or was subthreshold for $\mathrm{M}$ or $\mathrm{C}$ responses. In some studies, paired stimuli of equal or unequal intensity at intervals of 2 to $1,000 \mathrm{msec}$ were used to study the excitability (recovery) cycles of the

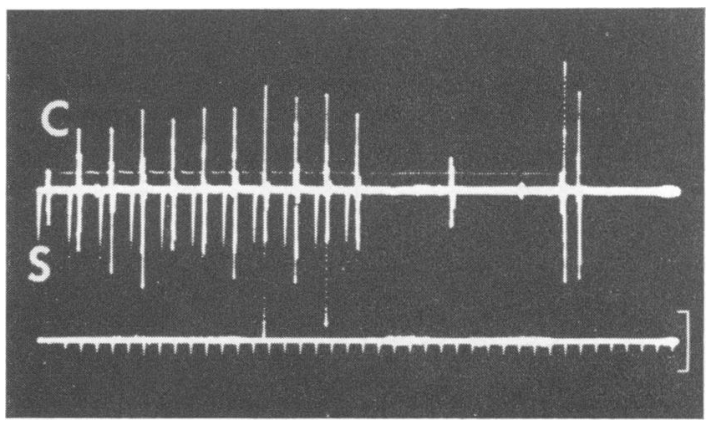

FIG. 3. Recordings of $C$ reflexes $(\mathrm{C})$ during repetitive stimulation (S) of the median nerve. Stimulus is subthreshold for $M$ response. Note augmentation of the $C$ reflex with stimulation at 5 per second for $2 \mathrm{sec}$. Calibration: $100 \mathrm{msec}$ and $400 \mu \mathrm{V}$. 


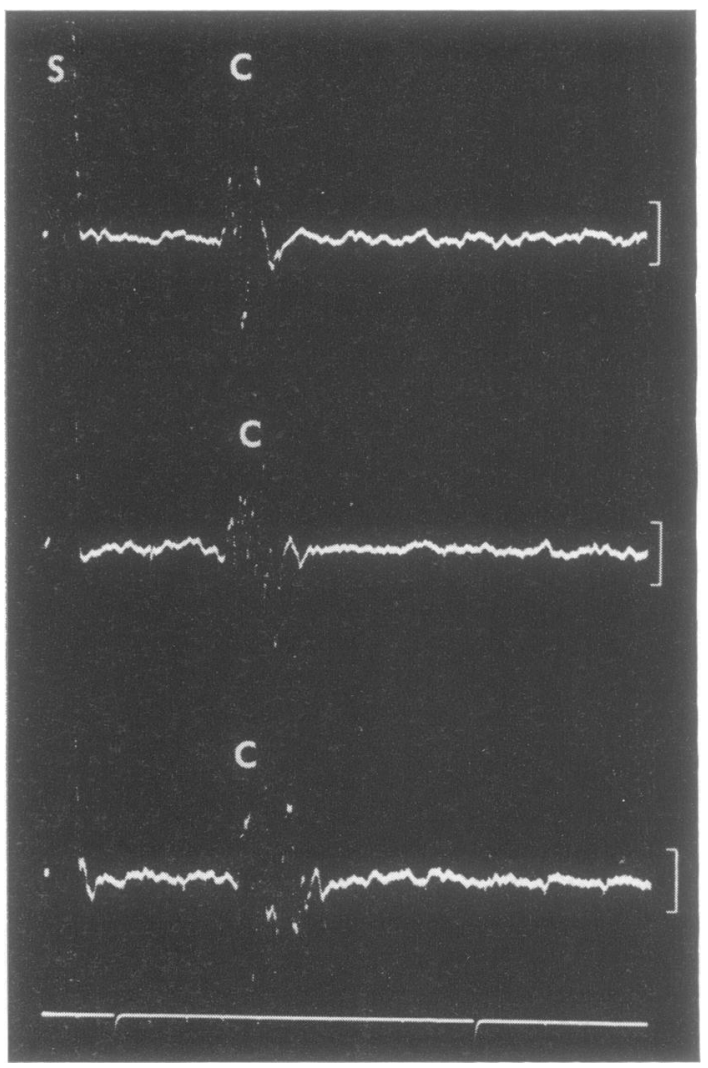

FIG. 4. Recordings of $C$ reflexes (C) from thenar muscles stimulating (S) median nerve at the wrist. Note the variability of single responses. Calibration: $100 \mathrm{msec}$ and $200 \mu \mathrm{V}$.

responses. Recordings were made with surface electrodes; the electrical activity was amplified, displayed on a Tektronix oscilloscope and photographed. In some studies, 30 responses separated by intervals of 10 seconds were summed with a computer (CAT $400 \mathrm{~A}$ ). In others, three to five $\mathrm{C}$ reflexes were superimposed during photography or with a Tektronix storage oscilloscope.

Cortical somatosensory evoked responses (SER) were recorded over the hemisphere contralateral to the stimulated hand with one electrode $2 \mathrm{~cm}$ posterior to the vertex and $7 \mathrm{~cm}$ lateral to the midline and the other on the ear. The stimulus and recording techniques of the SER were the same as those used to record the $\mathrm{C}$ reflex and both responses were recorded simultaneously.

Recordings were performed in a quiet warm laboratory with the patient awake and during intramuscular diazepam (Valium) or oral quinalbarbitone (Seconal) sedation and sleep. The studies were performed throughout a period of two years while the patient was being evaluated and treated.

\section{RESULTS}

The conduction velocity in efferent fibres of the right median nerve (elbow to wrist) was $54 \mathrm{~m} / \mathrm{sec}$ and the velocity in the fastest afferent fibres in 0 the same nerve segment was $56 \mathrm{~m} / \mathrm{sec}$. These velocities are within normal limits for the patient's age (Mayer, 1963).

$\mathrm{H}$ reflexes could be recorded in calf muscles क and no $\mathrm{H}$ reflex was present in hand or foot $\overrightarrow{0}$ muscles as is characteristic of normal adults (Magladery and McDougal, 1950; Mayer and $\vec{\omega}$ Mawdsley, 1965). The $\mathrm{H}$ reflexes recorded in the right triceps surae muscle had a normal latency of $27 \mathrm{msec}$. The excitability cycle of the $\mathrm{H}$ reflex, as tested with paired stimuli, showed a more rapid recovery than normal. This type of cycle 0 occurs in patients with chronic hemiplegia an ${ }^{\circ}$ o hyperreflexia (Magladery et al., 1952; Garcia袖 Mullin and Mayer, 1972) and reflects increase motoneurone excitability.

An antidromic motor $F$ response was presen in hand and foot muscles and was normal in. amplitude and frequency of occurrence. The latency of the $F$ wave recorded in thenar muscles after stimulation of the median nerve at the wrist was $27 \mathrm{msec}$ (normal 25-34 $\mathrm{msec}$ ).

C REFLEX The action potential of the $\mathrm{C}$ reflex was similar in form and duration to many of the $\triangle$ spontaneously occurring myoclonic jerks. Both $\overline{\bar{o}}$ could be evoked by electrical stimulation of a mixed motor-sensory nerve or a sensory digital nerve as well as by tactile (cotton, finger, etc.), nociceptive (pinprick), and proprioceptive (eliciting tendon jerks) stimuli (Fig. 1). Associated and direct movements produced marked augmenta- 3 tion of both amplitude and frequency of the myoclonic jerks (Fig. 2). The amplitude of the $\mathrm{C}$ reflex was increased by repetitive electrical or 0 other stimuli especially at rates of 5 to $30 / \mathrm{sec}$ (Fig. 3). The $\mathrm{C}$ reflex was most easily recorded in the right hand muscles where the myoclonus was most prominent. It was also recorded in the right foot, rarely in the right calf but not in the left 0 hand muscles. The response was decreased or $\omega$ 
obliterated by drowsiness, sleep and strong extension of the recorded muscle.

Stimulating the right median nerve at the
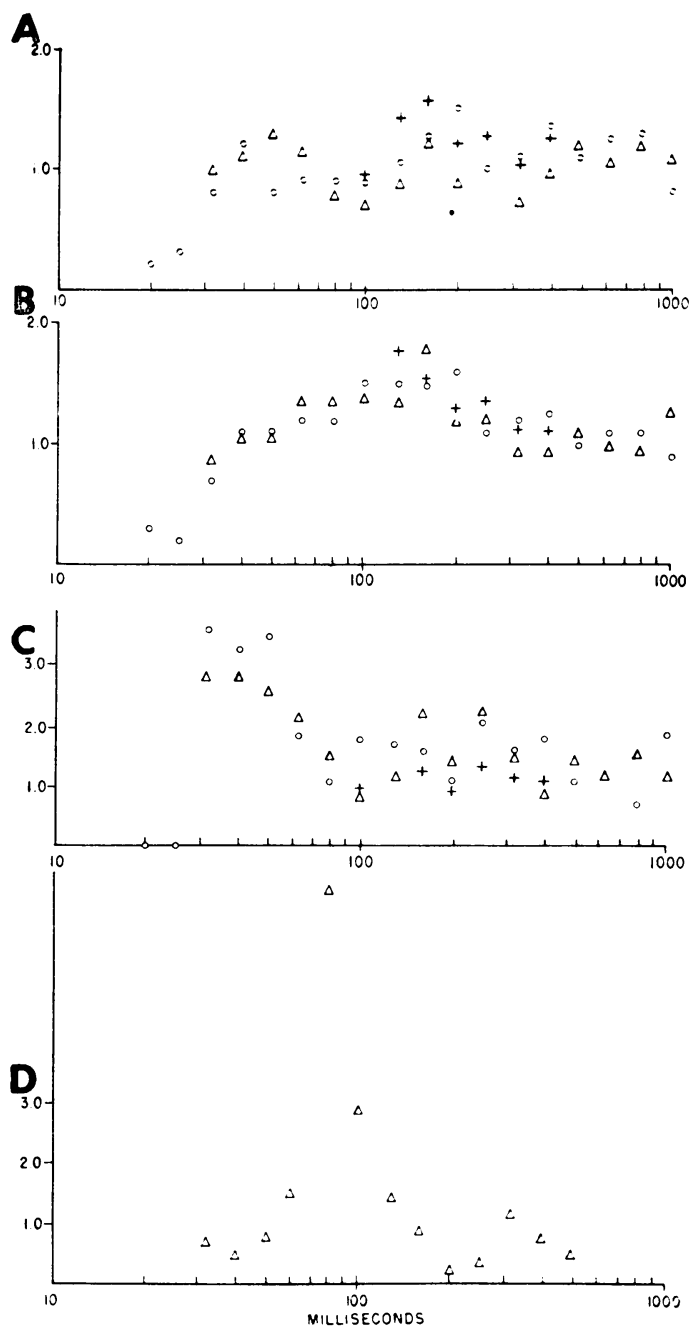

FIG. 5. Excitability of somatosensory evoked responses and long loop C reflex, (A) initial large positive deflection of $S E R$, (B) positive to negative segment of $S E R$, (C) first response of a double $C$ reflex measured from first negative peak to subsequent positive peak, and (D) second C response. The ordinate is the ratio of the second response to the first following paired stimulation of the right median nerve at the wrist. The abcissa is the interval between the paired stimuli in milliseconds. $+: M$ response just present on 30 January 1970. $\triangle$ : Just below $M$ response on 10 July 1970. $\bigcirc:$ Just below $M$ response on 30 October 1971. wrist with an electrical stimulus subthreshold for motor fibres evoked a small triphasic or polyphasic $\mathrm{C}$ reflex in the thenar muscles. The amplitude of the response varied from 250 to $1,500 \mu \mathrm{V}$ and the mean latency of the reflex recorded on six different days was $51 \mathrm{msec}$ with a range of 48-54 msec (Fig. 4). The latency of the reflex decreased as the nerve was stimulated more proximally. The conduction velocity in the fastest fibres subserving the $\mathrm{C}$ reflex from wrist to elbow was obtained by subtraction. In afferent fibres, this was 50 to $56 \mathrm{~m} / \mathrm{sec}$, a speed which is similar to that of the fastest sensory and motor fibres in the median nerve. Since the latency of

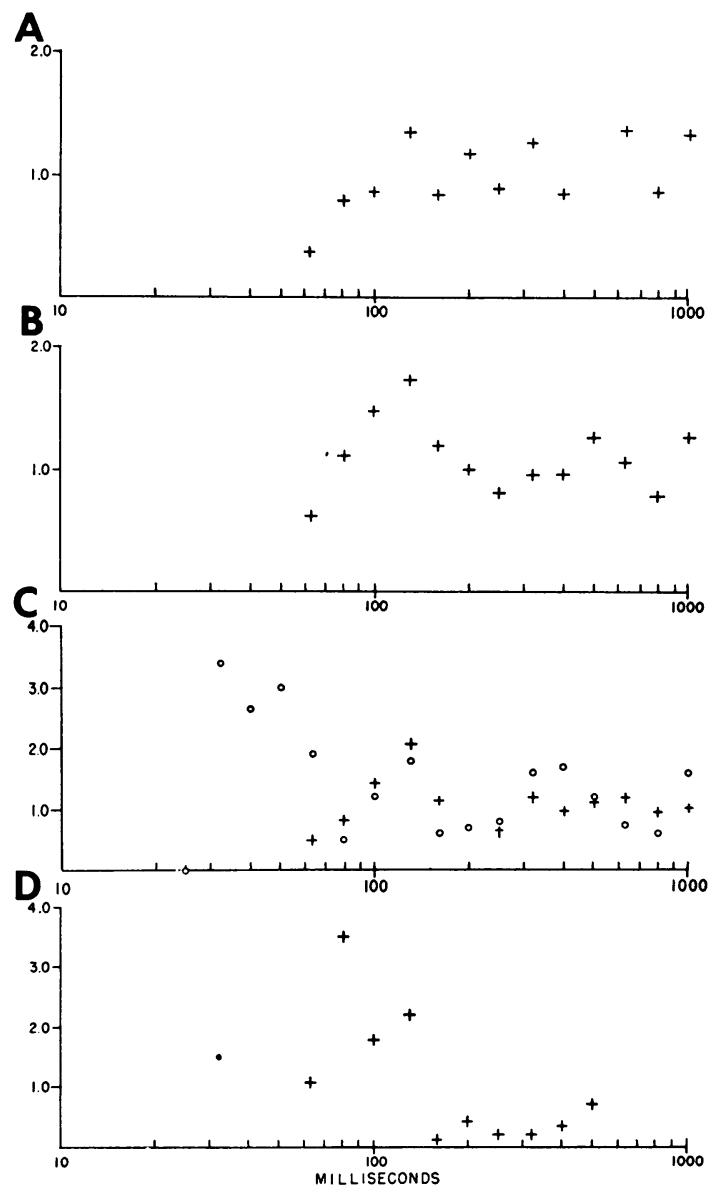

FIG. 6. Excitability cycles of somatosensory evoked responses and $C$ reflex as in Fig. 5, except stimulus is to the sensory nerves in the right index finger. $+: 3$ July 1970. O: 14 October 1972. 
the $F$ response $(27 \mathrm{msec})$ is the time it takes impulses in rapidly conducting motor fibres to travel to and from spinal motoneurones, the remaining $24 \mathrm{msec}$ (range 21-27) of the $\mathrm{C}$ reflex represents conduction in central pathways. The latency of the SER from wrist to contralateral parietal lobe was $24 \mathrm{msec}$ with approximately $12 \mathrm{msec}$ peripheral time and the remaining $12 \mathrm{msec}$ central time. Therefore, the $24 \mathrm{msec}$ central time of the $\mathrm{C}$ reflex is sufficient to permit impulses to travel from cervical spinal segments to and from sensory and motor cortex with additional synapses only in dorsal column nuclei and thalamus.

When the response was recorded in plantar foot muscles after stimulating the posterior tibial nerve at the ankle, the latency was $103 \mathrm{msec}$ and the latency of the $F$ response was $55 \mathrm{msec}$. By subtraction, this leaves $48 \mathrm{msec}$ for conduction centrally of the $\mathrm{C}$ reflex to and from the cortex from the $L_{5}-S_{1}$ spinal segments.

Excitability cycles of the $\mathrm{C}$ reflex using paired equal electrical stimuli just below threshold for the $M$ response applied to the mixed motorsensory fibres of the median nerve at the wrist are shown in Fig. 5C. A biphasic recovery curve occurred with maximal augmentation of the $\mathrm{C}$ reflex during the first phase at 32 through 80 msec. The second phase lasted from 130 to approximately $300 \mathrm{msec}$ in some, while in others the $\mathrm{C}$ reflex usually remained augmented and fluctuated from 100 to $1,000 \mathrm{msec}$. The excitability cycles varied somewhat from day to day, especially when the responses consisted of three to five superimposed tracings, probably reflecting the variability of individual responses which depend on the behavioural (voluntary and reflex) state of the patient. In one study using equal stimuli just below threshold for the $\mathbf{M}$ response, the recording muscle was stretched passively during the recovery cycle. This produced increased augmentation of the $\mathrm{C}$ reflex and the second phase persisted for over $500 \mathrm{msec}$. With paired equal stimuli sufficient to produce an $M$ response, there was less augmentation during the second phase. When the conditioning shock was subthreshold for the $\mathrm{C}$ reflex and the test shock was just below threshold for the $M$ response, the excitability cycle had a very short second phase with little augmentation after 150 msec.
If the sensory fibres of the median nerve were stimulated in the digits the recovery cycles were similar although they appeared polyphasic. The first phase of augmentation, which was the greatest, occurred at 32 through $63 \mathrm{msec}$ with the second phase at 100 through $130 \mathrm{msec}$ and a third phase starting at $320 \mathrm{msec}$ (Fig. 6C).

On several occasions the response consisted of two potentials separated by 35 to $50 \mathrm{msec}$. The excitability cycles of the second $\mathrm{C}$ reflex of $\mathrm{a}$ 들 double response were obtained during paired stimulation of the right median nerve, once at $\frac{\text { के }}{\widetilde{\sigma}}$

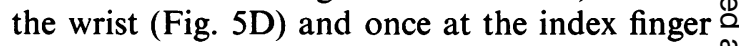
(Fig. 6D). Augmentation of the second $\mathrm{C}$ reflex के was not biphasic, occurred later than the first $\mathrm{C} \overrightarrow{0}$ reflex, and was maximal at $80 \mathrm{msec}$.

SOMATOSENSORY EVOKED RESPONSES (SER) The $\frac{0}{5}$ electrically evoked somatosensory response was? very large and usually consisted of a large positive wave followed by a large negative wave (Fig in
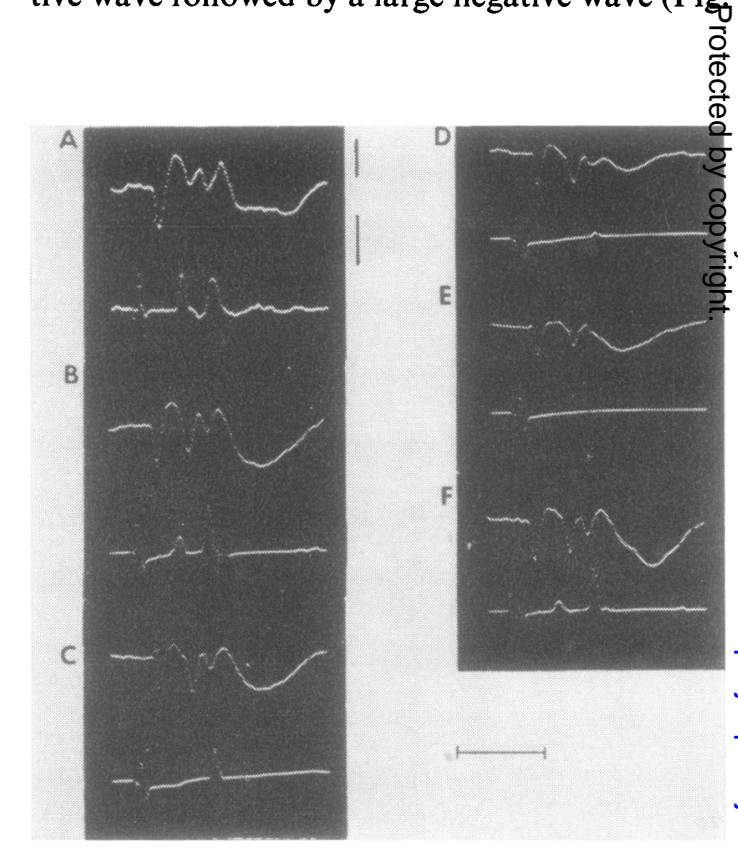

FIG. 7. Recording of SER (upper trace) and $C$ reflex (lower trace). (A) Patient is awake. (B-E) During drowsiness through light sleep. (F) After arousal. A $\frac{D}{0}$ downward deflection represents positivity at the active electrode. Thirty single stimuli were delivered to the $\mathrm{N}$ right median nerve at the wrist. Analysis time is 250 msec. Calibration: upper trace $=50 \mu \mathrm{V}$ and lower trace $=1 \mathrm{mV}$. Time line $=100 \mathrm{msec}$. 
7A). With a stimulus just subthreshold for motor fibres applied to the right median nerve at the wrist, the amplitude of the first large positive wave was 36 to $50 \mu \mathrm{V}$ (normal values up to $7 \mu \mathrm{V}$ (Halliday, 1967b)) and the subsequent positive to negative deflection was 70 to $99 \mu \mathrm{V}$. The amplitude of the SER evoked over the right hemisphere by the same intensity stimulation of the left median nerve was about one-third of the above described values. The latency to the onset of the first large positive deflection of the SER from the right median nerve at the wrist to the left parietal area was $24 \mathrm{msec}$ (average of 12 SER, each consisting of 30 summated responses) with a range of 21 to $26 \mathrm{msec}$ (normal value 18 to 21 msec (Giblin, 1964)).

The ratio of the amplitudes of the first large positive deflection of the SER recording simultaneously at the hand sensory area and points $4 \mathrm{~cm}$ anterior, $8 \mathrm{~cm}$ anterior, and $4 \mathrm{~cm}$ posterior was $1 / 0 \cdot 55 / 0 \cdot 53 / 0 \cdot 88$. Correspondingly for the subsequent positive to negative segment, the ratio was $1 / 0 \cdot 91 / 0 \cdot 48 / 0 \cdot 60$.

Excitability cycles of the first large positive deflection of the SER using paired equal electrical stimuli just below threshold for the $M$ response applied to the mixed motor-sensory fibres of the median nerve at the wrist were biphasic like those of the $\mathrm{C}$ reflex (Fig. 5A). However, there was a lesser degree of augmentation of the SER, particularly the first phase, as compared with the $\mathrm{C}$ reflex upon stimulating either the mixed motorsensory nerve or the digital sensory nerve (Fig. 6A). The excitability cycle of the positive to negative segment of the SER evoked by stimulation of the right median nerve at the wrist was not clearly biphasic.

Simultaneously recorded EEG and EMG from the thenar muscles of the right hand revealed myoclonic jerks in these muscles which often occurred approximately at the same time after the spike discharge in the left hemisphere somatosensory area, whether occurring spontaneously or evoked by stimulation of the right median nerve.

SLEEP During sleep, the myoclonus as well as the $\mathrm{C}$ reflex was depressed. The effects of diazepam and quinalbarbitone upon the SER and C reflex were studied. The effect of $10 \mathrm{mg}$ diazepam intramuscularly was evaluated at a time when there was a double SER and C reflex with stimuli to the right median nerve. Shortly after injection the patient drifted into light sleep. The first $\mathrm{C}$ reflex was most rapidly attenuated, reaching half of its control value when the second $C$ reflex was unaffected and the SER only slightly reduced (Fig. 7B). The first $\mathrm{C}$ reflex and then the second $\mathrm{C}$ reflex disappeared, at which time the first large positive wave of the first SER was $75 \%$ of the control response, and the subsequent

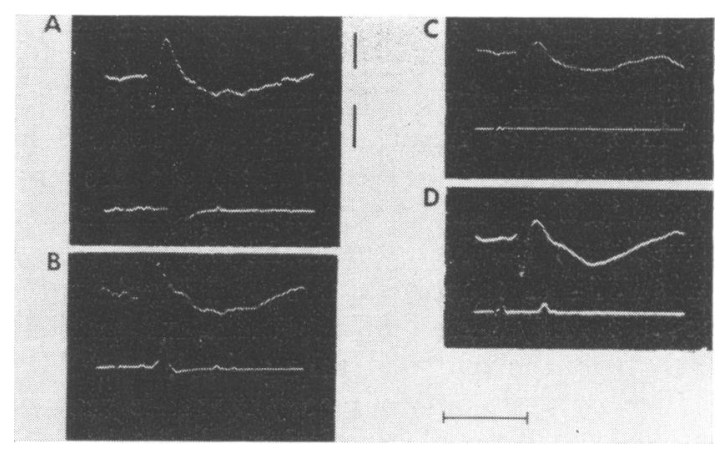

FIG. 8. Recordings of SER (upper trace) and C reflex (lower trace) as in Fig. 7. (A) Awake. (B) Drowsiness after $100 \mathrm{mg}$ quinalbarbitone by mouth. (C) Light sleep. (D) After arousal. Calibration: upper trace= $50 \mu \mathrm{V}$ and lower trace $=1 \mathrm{mV}$. Time line $=100 \mathrm{msec}$.

positive to negative segment was $50 \%$. After arousal the first $\mathrm{C}$ reflex was $25 \%$, and the positive to negative segment of the first cortical response was $70 \%$ of the control values, whereas the second $\mathrm{C}$ reflex and the first large positive wave of the first SER were almost back to their control values. The administration of the $100 \mathrm{mg}$ quinalbarbitone by mouth at a time when a single SER and $C$ reflex were present produced changes similar to those with diazepam (Fig. 8).

\section{DISCUSSION}

The patient described in this report demonstrates myoclonus which is limited to the right side of the body and occurs during voluntary motor and reflex activation. We have preferred to use the term 'reflex myoclonus' to describe the muscle contractions, since they are both activated and 
augmented by reflex stimulation as well as by voluntary contraction of muscle. The localization of myoclonus to a hemiplegic side is less common than generalized myoclonic contractions which occur in many metabolic as well as degenerative disorders. We therefore have used the term 'focal reflex myoclonus' to describe the motor activity presented here until the basic mechanism is known. This type of myoclonus has also been classified as the 'pyramidal' type by Halliday (1967b), since the myoclonic jerks were focal, were usually preceded by a cortical spike, and the major lesion probably involved the cortical-subcortical area of the contralateral hemisphere.

Our patient also exhibits many of the features of intention or action myoclonus described by Lance and Adams (1963). These authors proposed 'that the mechanism of intention or action myoclonus involves synchronous or repetitive firing of thalamocortical fibres arising from the specific relay nuclei of the thalamus, particularly from the ventrolateral nucleus'.

The normal somatosensory response may be evoked by electrical stimulation of mixed nerves or of sensory nerves in the fingers, and even by tapping (Larsson and Prevec, 1970; Calmes and Cracco, 1971). The pathway is through peripheral nerve, dorsal funiculus of spinal cord, contralateral ventroposterior (VP) nucleus of the thalamus, and sensorimotor cortex. Domino et al. (1965) found that lesions limited to the ventrolateral (VL) nucleus of the thalamus in patients with involuntary movement disorders produced no significant change in the SER. If the lesion extended into VP nucleus, then the SER was attenuated. Other investigators (Halliday, 1967a; Williamson et al., 1967; Stohr and Goldring, 1969) have demonstrated that interruption of the lemniscal system decreased or abolished both the early and late portions of the SER. As in the normal subject, the huge SER in our patient could be evoked by stimulation of either a mixed nerve or a sensory digital nerve. Therefore, stimulation of muscle afferent nerve fibres is not required.

It is suggested that the pathway of the large cortical evoked response for our patient is the same as that of the normal SER. This is in accord with a recent study by Pagni et al. (1971) who studied stimulus sensitive myoclonus in two patients with Lundborg-Unverricht syndrome with recording and stimulating electrodes placed in the sensorimotor cortex and pallidum internum, ventroposterolateral (VPL), and VL ${ }^{\circ}$ thalamic nuclei, internal capsule, and nucleus ruber. They concluded that the afferent volley evoking the myoclonus travels through the dorsal funiculus of the spinal cord, contralateral VP nucleus of the thalamus, sensorimotor cortex, and corticospinal tracts bilaterally.

Studies of the SER and long loop C reflex in our patient indicate that there is sufficient time to traverse this afferent pathway as well as an efferent arc down the corticospinal tract. However, such a cortical pathway may not be the only or primary long loop, and subcorticalextrapyramidal pathways may be important. Although the electrically evoked myoclonic jerks studied are preceded by a cortical discharge, there are some spontaneous ones which are not.

Jung and Hassler (1960) have reported inẹ stances of improvement in myoclonus afte\$ stereotaxic thalamotomy, but Lance (1968 stated that the four patients in his series did no improve after placement of a lesion in the VB nucleus of thalamus. In addition, Lhermitte al. (1971) in a stereotaxic study of a patient wite. post-anoxic intention or action myoclonus con cluded that myoclonus was related to paroxysmal discharges along the corticospinal tract, that motor cortical discharges were followed and never preceded by spikes in the ventrolateral nucleus of the thalamus, that stimulation of the VL nucleus did not modify cortical activity or evoked myoclonus, and that destruction of the VL nucleus had no effect on myoclonus.

If increased myoclonus with intention occurs through stimulation of muscle stretch receptors, either the dentatorubrothalamic pathway may be partially intact or there may be an alternative route. Evidence for projection of muscle stretch afferent fibres over the lemniscal system via the thalamus to the cortex, independent of the spinocerebellar-thalamocortical pathways, has been $O$ presented by Oscarsson and Rosen (1966) and Mallart (1968) for the forelimb of the cat. The group I afferent fibres ascend in the dorsal of funiculus, relay in the cuneate nucleus, and terminate in VPL more medial, rostral, and dorsal than the cutaneous projections. These 
fibres then project to Brodmann's areas $3 \mathrm{a}$ and a caudal part of 4 . In the monkey, both forelimb and hindlimb group I muscle afferent fibres project to sensorimotor cortex.

The shape of the huge SER in our patient does not conform closely to that in normal subjects. Using the nomenclature of Goff et al. (1969), $P_{2 a}$ and $\mathrm{P}_{3 \mathrm{a}}$ most nearly correspond to the initial large positive wave and $\mathrm{N}_{3 \mathrm{~b}}$ to the subsequent negative wave. $\mathrm{P}_{2 \mathrm{a}}$ and $\mathrm{P}_{3 \mathrm{a}}$ are restricted to the general locus of the somatosensory area in the contralateral posterior parietal cortex. Recording transcortically in man, Goldring et al. (1970) found that some show no contralateral sensory input to the motor cortex, whereas others show only an S1 type projection or a response of slightly longer latency. Both segments of the SER in our patient have maximal amplitudes at the somatosensory area. However, the initial positive wave has a relatively greater posterior distribution in comparison with the subsequent negative wave. The maxima of the large positive wave of Dawson's (1947) patient occurred $3 \mathrm{~cm}$ anterior to the surface marking of the central sulcus.

That portion of the normal SER most nearly corresponding to the first large positive deflection of the abnormal response approaches recovery by approximately $200 \mathrm{msec}$ (Allison, 1961). This differs from the data of Shagass and Schwartz (1963) in which $P_{2 a}$ and the segment $\mathrm{N}_{2 \mathrm{~b}}-\mathrm{P}_{3 \mathrm{a}}$ reach about $60 \%$ of their control values within a few milliseconds. $P_{2 a}$ approaches full recovery by about $50 \mathrm{msec}$, whereas the segment $\mathrm{N}_{2 b}-\mathrm{P}_{3 \mathrm{a}}$ has not reached full recovery by 100 msec. The excitability curve of the first large positive deflection of our patient was biphasic with recovery by $32 \mathrm{msec}$, mild augmentation from 32 to $63 \mathrm{msec}$ and from 130 to at least 250 msec. This differs from Dawson's (1947) and Giblin's (Halliday, 1967b) patients principally in that there was some augmentation rather than depression with interstimulus intervals between 100-300 msec.

In our patient, the presence of a long loop C reflex and a large SER with little change in monosynaptic $H$ reflexes and antidromic motor $F$ responses in hand muscles suggests increased excitability of neurones rostral to spinal motoneurones. However, it is not clear how and at which central synapse of the long loop there is increased excitability. Obviously there is increased excitability along the afferent pathway. Clinically, our patient's major lesion is a large atrophic one involving the left frontotemporoparietal region producing dysfunction at the neocortical level. There is lesser clinical evidence of involvement of pathways through the right superior cerebellar peduncle. The combination of these two lesions may be necessary for the production of focal reflex myoclonus. Lance and Adams (1963) stated that intention myoclonus was invariably associated with cerebellar dysfunction which may alter the thalamocortical discharge. This may be present in our patient, but it is unlikely that there is dysfunction of the lower brain-stem reticular formation, such as the nucleus gigantocellularis, which may be necessary for the production of the generalized myoclonus which occurs in experimental urea infusion (Zuckermann and Glaser, 1972) and in human uraemia.

An animal experimental model suggesting that myoclonus may represent a release phenomenon has been produced by Milhorat (1967) in the monkey by excision of the medial thalamus. Unilateral mesial thalamectomy produced highvoltage slow and sharp waves accompanied by bursts of spikes largely confined to the ipsilateral cerebral hemisphere. In four of eight such monkeys there was myoclonus involving the side of the body contralateral to the lesion and often synchronous with the bursts of spikes from the thalamectomized hemisphere. The lateral thalamus was excised in three animals with myoclonus five to seven days after lesions of the mesial thalamus. The myoclonus was abolished, but there was little change in the postoperative EEG.

Skinner and Lindsley (1971) nave demonstrated that cryogenic blockade of the nonspecific thalamocortical system in the cat creates an enhancement of both visual and auditory evoked potentials. There was enhancement of the first positive peak of the optic radiation evoked response, implying both a greater transmission through the lateral geniculate body and a larger cortical response to a constant afferent input.

Recent experimental evidence in the cat supports a significant influence of the cerebellum on the SER. Boone (1972) reported that stimulation 
at $300 \mathrm{~Hz}$ of the deep cerebellar nuclei, particularly the fastigial, produced ipsilateral depression of both visual and somatosensory evoked responses at the corresponding primary cortical sensory areas but not in the reticular formation. This attenuation was thought to be mediated through the uncinate fasciculus at a thalamic level. Evoked potential studies by Heath (1972) demonstrated direct connections between the fastigial nucleus and the ipsilateral ventroposterolateral thalamic nucleus.

On several occasions in our patient, a single stimulus to the right median nerve evoked a double response of both the SER and C reflex separated by an interval of approximately 35$50 \mathrm{msec}$ (Fig. 7). The second response presumably follows the first at this interval because there is an augmentation of the recovery cycle from $32-63 \mathrm{msec}$. There is much greater augmentation of the $\mathrm{C}$ response than the SER, which suggests that there is augmentation of the long loop response not only in the afferent arc, but also in either the afferent-efferent or efferent pathway. This also provides a plausible explanation of why diazepam produces a more rapid attenuation of the first $\mathrm{C}$ reflex than the second. This may occur because the second SER which is only slightly attenuated evokes the second $\mathrm{C}$ reflex during the period of marked augmentation. These findings further suggest that much of the attenuation of the $\mathrm{C}$ reflex by diazepam occurs in the afferent-efferent or efferent pathway.

Diazepam (Ebe et al., 1969), quinalbarbitone, and sleep attenuated both the SER and especially the long loop $\mathrm{C}$ reflex. This is in agreement with Gath (1969) who found that treatment with nitrazepam in one of two patients with progressive myoclonic epilepsy produced a significant decrease in amplitude of the SER with corresponding clinical improvement. In our patient, long-term oral diazepam had little clinical effect on the myoclonic seizures.

\section{REFERENCES}

Allison, T. (1962). Recovery functions of somatosensory evoked responses in man. Electroencephalography and Clinical Neurophysiology, 14, 331-343.

Boone, S. C. (1972). American EEG Society, 25th Annual Meeting.

Calmes, R. L., and Cracco, R. Q. (1971). Comparison of somatosensory and somatomotor evoked responses to median nerve and digital nerve stimulation. Electroencephalography and Clinical Neurophysiology, 31, 547-562.
Dawson, G. D. (1947). Investigations on a patient subject to myoclonic seizures after sensory stimulation. Journal of Neurology, Neurosurgery, and Psychiatry, 10, 141-162.

Domino, E. F., Matsuoka, S., Waltz, J., and Cooper, I. S. (1965). Effects of cryogenic thalamic lesions on the somesthetic evoked response in man. Electroencephalography and Clinical Neurophysiology, 19, 127-138.

Ebe, M., Meier-Ewert, K.-H., and Broughton, R. (1969). Effects of intravenous diazepam (Valium) upon evoked potentials of photosensitive epileptic and normal subjects. Electroencephalography and Clinical Neurophysiology, 27, 429-435.

Garcia-Mullin, R., and Mayer, R. F. (1972). H reflexes in acute and chronic hemiplegia. Brain, 95, 559-572.

Gath, I. (1969). Effect of drugs on the somatosensory evoked potentials in myoclonic epilepsy. Archives of Neurology, 20, 354-357.

Giblin, D. R. (1964). Somatosensory evoked potentials in healthy subjects and in patients with lesions of the nervous system. Annals of the New York Academy of Sciences, 112, 93-142.

Goff, W. R., Matsumiya, Y., Allison, T., and Goff, G. D. (1969). Cross-modality comparisons of average evoked potentials. In Average Evoked Potentials: Methods, Results, and Evaluations, pp. 95-141. Edited by E. Donchin and D. B. Lindsley. NASA-SP-191. U.S. Government Printing Office: Washington.

Goldring, S., Aras, E., and Weber, P. C. (1970). Comparative study of sensory input to motor cortex in animals and mano Electroencephalography and Clinical Neurophysiology, 29 537-550.

Halliday, A. M. (1967a). Changes in the form of cerebra evoked responses in man associated with various lesions of the nervous system. Electroencephalography and Clinict Neurophysiology, Suppl. 25, pp. 178-192.

Halliday, A. M. (1967b). The electrophysiological study myoclonus in man. Brain, 90, 241-284.

Heath, R. G. (1972). Physiologic basis of emotional express sion: evoked potential and mirror focus studies in rhesus monkeys. Biological Psychiatry, 5, 15-31.

Jung, R., and Hassler, R. (1950). The extrapyramidal motor system. In Handbook of Physiology, pp. 863-927. Section I, Neurophysiology. Vol. 2. Edited by J. Field. American Physiological Society: Washington.

Lance, J. W., and Adams, R. D. (1963). The syndrome of intention or action myoclonus as a sequel to hypoxic encephalopathy. Brain, 86, 111-136.

Lance, J. W. (1968). Myoclonic jerks and falls: aetiology, classification and treatment. Medical Journal of Australia, 1, 113-120.

Larsson, L.-E., and Prevec, T. S. (1970). Somato-sensory response to mechanical stimulation as recorded in the human EEG. Electroencephalography and Clinical Neurophysiology, 28, 162-172.

Lhermitte, F., Talairach, J., Buser, P., Gautier, J.-C., Bancaud, J., Gras, R., and Truelle, J.-L. (1971). Myoclonies d'intention et d'action post-anoxiques. Étude stéréotaxique et destruction du noyau ventral latéral du thalamus. Revue Neurologique, 124, 5-20.

Magladery, J. W., and McDougal, D. B., Jr. (1950). Electrophysiological studies of nerve and reflex activity in normal man. I. Identification of certain reflexes in the electromyogram and the conduction velocity of peripheral nerve fibres. Bulletin of the Johns Hopkins Hospital, 86, 265-290.

Magladery, J. W., Teasdall, R. D., Park, A. M., and Languth, H. W. (1952). Electrophysiological studies of reflex activity in patients with lesions of the nervous system. I. A comparison of spinal motoneurone excitability following afferent nerve volleys in normal persons and patients with 
upper motor neurone lesions. Bulletin of the Johns Hopkins Hospital, 91, 219-244.

Mallart, A. (1968). Thalamic projection of muscle nerve afferents in the cat. Journal of Physiology, 194, 337-353.

Mayer, R. F. (1963). Nerve conduction studies in man. Neurology (Minneap.), 13, 1021-1030.

Mayer, R. F., and Feldman, R. G. (1967). Observations on the nature of the $\mathrm{F}$ wave in man. Neurology (Minneap.), 17, 147-156.

Mayer, R. F., and Mawdsley, C. (1965). Studies in man and cat of the significance of the $\mathrm{H}$ wave. Journal of Neurology, Neurosurgery, and Psychiatry, 28, 201-211.

Milhorat, T. H. (1967). Experimental myoclonus of thalamic origin. Archives of Neurology, 17, 365-378.

Oscarsson, O., and Rosén, I. (1966). Short-latency projections to the cat's cerebral cortex from skin and muscle afferents in the contralateral forelimb. Journal of Physiology, 182, 164-184.

Pagni, C. A., Marossero, F., Cabrini, G., Ettore, G., and Infuso, L. (1971). Physiopathology of stimulus sensitive myoclonus: a stereo-EEG study. (Abstract.) Electroencephalography and Clinical Neurophysiology, 31, 176.
Shagass, C., and Schwartz, M. (1964). Recovery functions of somatosensory peripheral nerve and cerebral evoked responses in man. Electroencephalography and Clinical Neurophysiology, 17, 126-135.

Skinner, J. E., and Lindsley, D. B. (1971). Enhancement of visual and auditory evoked potentials during blockade of the non-specific thalamo-cortical system. Electroencephalography and Clinical Neurophysiology, 31, 1-6.

Stohr, P. E., and Goldring, S. (1969). Origin of somatosensory evoked scalp responses in man. Journal of Neurosurgery, 31, 117-127.

Watson, C. W., and Denny-Brown, D. (1955). Studies of the mechanism of stimulus-sensitive myoclonus in man. Electroencephalography and Clinical Neurophysiology, 7, 341-356.

Williamson, P. D., Goff, W. R., and Allison, T. (1970). Somato-sensory evoked responses in patients with unilateral cerebral lesions. Electroencephalography and Clinical Neurophysiology, 28, 566-575.

Zuckermann, E. G., and Glaser, G. H. (1972). Urea-induced myoclonic seizures. Archives of Neurology, 27, 14-28.

\section{Addendum}

Dr. Charles Suter recently investigated the auditory evoked response in this patient and found it to be normal. 